\title{
A Self-Consistent Sonification Method to Translate Amino Acid Sequences into Musical Compositions and Application in Protein Design using Artificial Intelligence
}

Chi-Hua $\mathrm{Yu}^{1}$, Zhao Qin ${ }^{1}$, Francisco J. Martin-Martinez ${ }^{1}$, and Markus J. Buehler ${ }^{1 *}$

${ }^{1}$ Laboratory for Atomistic and Molecular Mechanics (LAMM), Department of Civil and Environmental Engineering, Massachusetts Institute of Technology, 77 Massachusetts Ave. 1-290, Cambridge, Massachusetts 02139, United States of America

*Address correspondence to: mbuehler@MIT.EDU, +1.617.452.2750

Supporting Information 
Overview of files

\begin{tabular}{|c|c|c|c|c|}
\hline II & DFT BASED AA SOUNDS & File folder & & Sounds of all 20 amino acids (as individual files) \\
\hline 6. & 20 AA sweep - DFT & MP3 File & J & Sweep through all 20 amino acids (in one file) \\
\hline 6 & $5 g k 4$ & MP3 File & 7 & \\
\hline 6 & $5 x \mathrm{dj}$ & MP3 File & & \\
\hline 6) & $6 c j c$ & MP3 File & & \\
\hline 6) & $6 \mathrm{czg}$ & MP3 File & & Sonifications of existing protein structures, name \\
\hline 6 & $107 \mathrm{~m}$ & MP3 File & & indicates PDB identifier \\
\hline 6 & 1941 & MP3 File & & \\
\hline 6. & A.mp3 & MP3 File & & \\
\hline & last move 84 & MP3 File & $=$ & \\
\hline 6 & $\mathrm{AH}-1 \mathrm{gk} 4$ & MP3 File & & \\
\hline 6 & $\mathrm{AH}-5 \mathrm{xdj}$ & MP3 File & & \\
\hline 6 & AH - ALA-VAL & MP3 File & 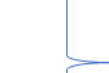 & Comnositions created bv $\mathrm{Al}$ \\
\hline ఠ & AHBS - ALA-VAL & MP3 File & & \\
\hline 6 & $B S-6 c z g$ & MP3 File & & \\
\hline 6 & BS - ALA-VAL & MP3 File & J & \\
\hline 冒 & ALL AAs - CHARMM - frequency data & Text Document & . & Frequency spectra file of all amino acids \\
\hline 冒 & ALL AAs - DFT - frequency data & Text Document & & (format: number, name of amino acid, frequency of modes $1 \ldots N$ \\
\hline di & AminoAcidPlayer App V3_May13 & & & Source code of the Android App \\
\hline
\end{tabular}

